\title{
The Use of Combined Models in the Construction of Foodstuffs Consumption Forecasting in the Czech Republic
}

\author{
Libuše Svatošová, Jana Köppelová \\ Faculty of Economics and Management, Czech University of Life Sciences Prague, Czech Republic
}

\begin{abstract}
Many authors all over the world attempt to perform time series analyses (at differing levels of expertise) in their published works. Knowledge of quantitative information is necessary for decision making in any domain. Therefore, it is more desirable to enter this field of problems and examine and develop everything that has been offered by these modern methodologies. In time series forecasting, the extrapolation methods are applied most frequently in practice. Currently, the combined models have been increasingly employed in experiments - these represent an aggregation of prognoses obtained from various separate models. The study presented is aimed at such new approaches, i.e. the construction of combined prediction models that are more realistic, more flexible and more concise in the time series modelling. This paper focuses on a subsequent assessment of combined prognoses constructed and a comparison of these with selected separate models having participated in the aggregate prognoses making. In order to obtain an efficient product, the Time Series Forecasting System (TSFS) component has been employed, being a component of the SAS programme system. For quality assessment of the models constructed, the assessment criteria selected in advance have been applied. The results of this empirical study have shown that in the domain of estimation of future foodstuffs consumption development, the techniques illustrated in this paper by examples of long-term time series from foodstuffs consumption area in the Czech Republic (CR), can be employed with success. This way represents a suitable supplement to complex econometric models.
\end{abstract}

\section{Keywords}

Foodstuffs consumption in the Czech Republic, time series analysis, exponential smoothing models, Box-Jenkins methodology, combined forecasting models.

Svatošová, L. and Köppelová, J. (2017) "The Use of Combined Models in the Construction of Foodstuffs Consumption Forecasting in the Czech Republic", AGRIS on-line Papers in Economics and Informatics, Vol. 9, No. 4, pp. 81-89. ISSN 1804-1930. DOI 10.7160/aol.2017.090408.

\section{Introduction}

The problem of foodstuffs consumption is always relevant and has been discussed at length and analysed from many different viewpoints. The indicators concerning foodstuffs consumption in the $\mathrm{CR}$ have been tracked by statisticians for almost a hundred years. The CSO (Czech Statistical Office) has continuous time series from foodstuffs consumption domain on domestic market available since 1948. This not only makes it possible to follow changes in the eating habits, but to increase precision of the forecasts constructed in this area, since a high quality forecast calls for the knowledge of quantitative information from this area. CSO monitors foodstuffs consumption by means of the Family account statistics (in separate households). Food consumption not only represents one of the fundamental human life necessities, but at the same time is one of the most important factors affecting the environment. For example, Notarnicola et al. (20160) have dealt with this in their works. They have concentrated on the assessment of the foodstuffs consumption effect on the environment in EU countries, using the consumer basket made up of selected foods and drinks (pork, beef, poultry, milk, cheese, butter, bread, sugar, sunflower oil, olive oil, potatoes, oranges, apples, mineral water, roasted coffee and beer) as the analysis tool.

As economists, it is important to be aware of the fact that farmland is an irreplaceable source of foodstuffs production (Pletichová and Gebeltová, 2013), and that foodstuffs are a necessary possession and the satisfaction of this vital need is a necessity for human life. Quality and quantity of foodstuffs represent the two fundamental factors capable of affecting the quality and length of life. Variety 
of eating habits differ in every country depending on the level of economics, demography, habits of the population, or on the level of agricultural production. This affects nutrition by its structure and by its absolute volume, then determining this way the quality and quantity structure of foodstuffs consumption. Smutka et al. (2009) performed an analysis of global foodstuffs consumption development and of global agrarian production as well. That included the tracking the global foodstuffs supply and demand development. Foodstuffs consumption can be examined and analysed from many viewpoints and sights. Olsen and Tuu (2017) focused their study on a comparison of values of healthy eating on one side and selfindulgence in eating on the other. This included the consideration of the future consequences of the Vietnamese teenagers' current consumption behaviour. De Vogli et al. (2014) analysed in their research the fast food consumption, specifically the influence of fast food consumption on BMI. Time series were collected from 25 member countries of the Organisation for Economic Co-operation and Development. Chen et al. (2010) directed their study at an analysis of food consumption in rural areas in China. The research was focused on agriculture land resources and the evaluation of such resources to ensure food security. Náglová and Horáková (2016) analysed one of the key food industry sectors in the CR, which is the meat industry. Their aim, by using a cluster analysis, was to define the quality factors limiting competitiveness of meat industry and the subsequent identification of groups of holdings having a key position.

Whether we are studying production, supply, demand or consumption of foodstuffs, quantitative information is vitally important to us. Quantitative information knowledge is necessary for decision making activities in any domain. Therefore it is necessary to operate within this field of problems and examine and develop everything that the modern methodology offers. Currently, the model tools for economic decision making support show an important path for both the basic and applied research in all the developed countries. The fundamental task of the models is to contribute to the solution of available data transformation problem in a given study area into the data needed (having a structure needed) for decision making at various levels. The time series theory belongs, particularly within the field of economic indicators, to the most significant quantitative methods. Forecasting of economic trends measures future development and plays an important role in the decision making process or in creating business strategies. That is the main target of this study, as well.

The central thesis of this paper is laid out in the examination of properties and the applicability of the separate prediction models offered by the SAS statistical system and subsequent combinations of these for the purpose of foodstuffs consumption forecasts making. There is a heavy emphasis on the study of combined models, possible ways of aggregation and application.

Outcomes of many studies targeted at time series forecasting of various economic indicators by means of aggregated predictions have shown that these modern techniques facilitate construction of more precise prognoses. The SAS system offers a rather wide choice of models, starting from the classical analytical models (Hindls et al., 2000 ), through adaptive models of exponential smoothing up to Box-Jenkins models. The study deals in particular with the assessment of the applicability of models constructed for description of the indicator's under study past development and subsequent extrapolation forecasts.

In his study, Kába (1997) dealt with economic indicators' time series properties examination, specifically with prognostic models' applicability analysis. However, in the study given, the number of these was limited. The SAS programme system is considered one of the best and most comprehensive statistical programme packets, that satisfies the condition of this study, i.e. to have a really wide choice of various models available. The TSFS (Time Series Forecasting System) offers several univariate time series models to users. The TSFS component facilitates construction of combined models in the form of a simple arithmetic average, as well as a weighted arithmetic average with various weights. At the same time it is possible to aggregate the forecasts based on arithmetic averages of the original time series values of the indicators under study, or by means of the logarithms' arithmetic average of the original values. As for the proper processing of the time series, it has been recommended by modern methodology to keep to a sequence of stages from primary collection, examination and purification of the data, through a preliminary analysis, design of candidates for the forecast formation needs, preliminary modelling including a precision stability test of the model, up to the final model selection and implementation 
(SAS/ETS User's Guide, Version 6, 1993). This research is focused predominantly on construction and assessment of combined models. This means that from the sequence given above, it will be focused on the stage including the design of suitable candidates for extrapolation forecast needs, inclusive of subsequent statement of precision and stability of the model. The models constructed will be assessed by means of assessment criteria selected in advance.

Techniques of combining the autoregressive (AR) models and the moving averages (MA) models have been applied in the analysis of univariate time series very frequently. The AR and MA models represent special types of the Box-Jenkins methodology. They can be applied both in interpolation as well as in the extrapolation of stationary time series. Through the combination of both of these model types, a so-called mixed model arises, or an ARMA model. However, for ARMA model use, stationarity of the time series is assumed (Martin et al., 2013). ARMA models were analysed by Barreras Serrano et al. (2014) in their study that focused on the analysis and forecasting of univariate time series of beef production in one specific area in Mexico. An augmented Dickey-Fuller test was used for verification of stationarity. In this case, ARMA models application on of real economic time series is required. The time series given should first be stationarized, since most time series does not satisfy the stationarity assumption. A suitable tool for such an adjustment is to obtain the differences of neighbouring values of the time series. An ARMA model applied in modelling of this already adjusted time series is denoted as ARIMA model - an integrated ARMA model (Cipra, 1986). Where the classical trend models fail, ARIMA models can be successfully applied in the description of such time series, as well. Thanks to this, the Box-Jenkins models have been widely applied in a variety of areas.

Köppelová and Jindrová (2017) have analysed as part of their work, the benefits of combined forecasts in the mobile telecom services consumption forecasting in the Czech Republic. The conclusions of this work suggest promising results in the use of combined models in forecasting operations in this area, be it through combination of models in the Box-Jenkins methodology, or in the exponential smoothing models. Christodoulos et al. (2011) concentrated on the exponential smoothing models in their analyses, specifically at the Holt's damped trend with a modification, Gompertz and Linear Logistic model and combination of these for the purpose of predicting broadband data connection in OECD countries. Tavakkoli et al. (2015) employed a combination of two models from the adaptive models class - specifically the Double and Holt Winters exponential smoothing - with the ARIMA models. They assessed the benefits of the approach given for particleboard consumption forecasting in Iran from 1978 to 2009. The combined methods were applied by $\mathrm{Xu}$ and Wang (2010) in the forecasting of natural gas consumption. In addition, Deb et al. (2017), utilized the combined methods in a study dealing with construction and an assessment of the combined models in buildings' energy consumption forecasting. They reached a conclusion showing that, the combined techniques are much more efficient in time series forecasting than others.

\section{Materials and methods}

For proper empirical analysis, data has been applied, having the character of time series and drawn from the Czech Statistical Office surveys resources. All in all, 73 time series of food consumption data with annual frequency have been analysed. The reference period covered the years of 1989 to 2015. The following food groups have been included in the analysis:

cereals and bakery products (15 items) meat in terms of carcass weight (10 items) milk, milk products, cheese and eggs (9 items) fats and oils (6 items) sugar, sweets and confectionary (7 items) non-alcoholic beverages (6 items) vegetables, pulses, potatoes (9 items) fruits in terms of fresh (11 items)

The process of looking for the optimal model for time series analysis and subsequent forecasting can often times be very demanding, particularly in terms of time. The Time Series Forecasting Systems module (TSFS), being part of the SAS programme system, allows its acceleration. It was this benefit, that was the deciding factor for applying it in our study.

All the forecasts can be constructed both in the point shape and in the interval shape. The SAS system stresses verification of applicability assumptions of the separate analytical and prognostic procedures and it offers a number of diagnostic tools for this purpose. In order to clarify which of the prognostic models implemented are suitable for the forecast generation, SAS performs a series of diagnostic 
tests (Log transform test, Trend test, Seasonality test) examining the analysed time series properties. These are sophisticated procedures (Arlt and Arltová, 2009) that are concerned with the assessment of the homoscedasticity of the residues. Furthermore, the presence of the trend component and the seasonality component is examined.

Based on the results of these tests, SAS selects and materializes appropriate corrective actions (log transformation, e.g., to stabilize the variance). It is important to mention that a specification of prognostic models by means of diagnostic tests as used in the SAS system, does not guarantee the establishment of a model with optimal properties. This is the initial stage only of the process of forecast construction, accelerating the whole process usefully, but needing a completion by additional checks and continuous verification of the outcomes obtained. By means of the SAS system selection criteria, all the time series have been identified and diagnosed automatically, and adequate forecasting models are constructed subsequently. At the first stage, individual (separate) models were only considered the most appropriate model and the forecast has been established. At the second stage, the three most appropriate individual models were considered, and based on the aggregation of these models, a combined model was set up. Both of these were in the shape of simple arithmetic averages and in the shape of weighted arithmetic averages with differing weights.

The forecast quality was then reviewed retrospectively by means of the test component of the corresponding time series (hold of sample evaluation). Accuracy of simulated predictions has been assessed by means of the Mean Absolute Percent Error metric (MAPE) and of the relative error of the prognosis $(r p)$, and then by the average relative error of the prognosis that are defined as

$$
\begin{aligned}
& \text { M.A.P.E. }=\frac{100}{n} \sum_{t=1}^{n}\left|\frac{y_{t}-y_{t}^{\prime}}{y_{t}}\right| \\
& r p=\frac{\left|y_{t}^{\prime}-y_{t}\right|}{y_{t}} \bullet 100
\end{aligned}
$$

where $y_{t}$ respectively $y_{t}^{\prime}(t=1,2, \ldots, n)$ are the actual or the smoothed values of the time series given and $\mathrm{n}$ represents the number of the time series observations. The pseudoprognosis has been established for three years. For each year of the estimate, the relative error of prognosis was evaluated and subsequently, for the overall quality assessment of the prognosis, the average relative error was obtained.

$M A P E$ represents one of the most frequently applied measures when assessing suitability of the models constructed for forecasts consisting of various indicators. The popularity of its use is due in particular to its form of expression, i.e. usually, usually as a percent.

$M A P E$ criterion for combined models assessment was used by Mamat et al. (2016), as well. They dealt with the testing of combined models for farm machinery performance prediction. MAPE was applied in Reboiro-Jato et al. (2011) study as well, in the assessment of models constructed for forecasting needs in the area of feed mixtures for livestock production. Gang and Weiguo's (2010) work was aimed at the assessment of the advantages or disadvantages of combined models and the use of these for the forecast of natural gas consumption in China. Papagera et al. (2014) used $M A P E$ in their research dealing with the forecasting of the indicators studied (indicators from the area of water supply changes) by means of Artificial Neural Networks (ANN).

As a further chance of quality assessment of the models constructed are the autocorrelation function $(\mathrm{ACF})$ and the partial autocorrelation function (PACF) graphs. Seger and Hindls (1993) have stated that, many residuals should be of the so-called white noise type, for the analytical models to be at all applicable. The outcome of the ACF supplies coefficients of correlation between the series $\mathrm{Y}_{\mathrm{t}}$ and $\mathrm{Y}_{\mathrm{t}-\mathrm{k}}$, where $t=2,3, \ldots, T$ and in graphical form also the $95 \%$ confidence intervals for the coefficients. These graphical ACF outcomes have been applied in the assessment of suitability of the models constructed for the time series studied. Considering the results presented in the next section it is obvious that the condition laid on the nature of series of the residues, has not been satisfied in all cases. In the overview of models, there are such a case where data had to first be adjusted using log transformation. These can be identified in the overview below, by the „Log“" preposition before the model name. Such a modification of the data is needed in case of the ACF value exceeding the confidence interval limit. In this case it means that the residuals needn't be of the white noise type (Sachs, 1984). 


\section{Results and discussion}

\section{Exploitation of the time series individual models}

In Table 1, an overall application of all the time series models is presented. It is obvious from the results presented that the case of the individual models use, the adaptive type models have been those most applicable. But it should be noted that the exponential smoothing models and the random walk model, presented in the results, are special cases of the ARIMA models. When parameters of these are estimated numerically, the SAS system applies the BoxJenkins methodology algorithms. Classical trend models have taken place exceptionally. These were the foodstuffs with slight consumption changes (rice, wheat flour, durable pastry, fish, milk and milk products, potatoes, honey).

\begin{tabular}{|l|c|}
\hline Model & $\begin{array}{c}\text { Absolute } \\
\text { representation }\end{array}$ \\
\hline Damped Trend Exponential Smoothing & 22 \\
\hline Linear (Holt) Exponential Smoothing & 18 \\
\hline Log Damped Trend Exponential Smoothing & 8 \\
\hline Double Browm Exponential Smoothing & 5 \\
\hline Log Simple Exponential Smoothing & 5 \\
\hline Log Linear (Holt ) Exponential Smoothing & 4 \\
\hline Log Linear Trend & 4 \\
\hline Random Walk with Drift & 3 \\
\hline Linear Trend & 3 \\
\hline Simple Exponential Smoothing & 1 \\
\hline
\end{tabular}

Source: Own processing based on data provided by Czech Statistical Office

Table 1: The best individual time series models of foodstuffs consumption.

Model quality has been assessed using $M A P E$ of the estimate. It was lower than $5 \%$ in the case of the 31 best individual models, and between $5 \%$ and $10 \%$ in the case of 24 models. 17 models had MAPE with slightly higher than $10 \%$. Based on these results, it can be stated that the models have been chosen adequately.

Considering the future development forecasts construction, it is important to assess quality of the forecasts, as well. Here, we needn't consider the same model, having been successful in the description of the indicator's current motion. For the forecast quality assessment, the time series was shortened by 3 years and the pseudoprognoses were set up for these 3 years. The relative error of the forecast was stated for each year compared and then the average relative error of the three, as well. Relative error values obtained for the separate years, same as the average relative errors confirm suitability for future development forecasting of the indicators studied, of the models given in the Table 1, in most cases.

The average relative error of the forecast value was less than $5 \%$ in the 42 time series given. In case of the 24 indicators that followed, the error value fluctuated between 5 and $10 \%$ and the average relative error of the forecast above $10 \%$ was obtained in the case of the following indicators: other cereals, rye flour, hops, durable pastry, game, canned milk, tea, garlic, pears, apricots.

\section{Combined time series models construction for foodstuffs consumption}

At the second stage of foodstuffs consumption development analyses, the combined model construction was adopted. Table 2 shows an overview of individual models entering the combined models construction process, inclusive of percentages of their representation. This analysis is directed at an assessment demonstrating whether combined model application actually can improve the forecast quality. Considering that the MAPE size three most suitable models are selected, the combined model is set up and its quality assessed by means of MAPE. Then the pseudoprognosis for three years is applied again and its quality assessed by means of the relative error of the forecast.

In the combined models construction, both of the two possible ways offered by the SAS system have been utilized. This means the simple aggregation way and the way of aggregation with regression weights. In both cases the $M A P E$ measure reached a value of lower than $5 \%$ in 32 models constructed. In 22 models aggregated the simple way and 21 models with regression weights, the value of the error fluctuated between 5 and $10 \%$. When assessing the forecast quality, the relative error of the forecast in the combined models with equal weights was lower than $5 \%$ in 45 models. In the combined models with regression weights, the same value of the relative error of the forecast, i.e., a value lower than $5 \%$, was reached for 42 models. Twenty-one combined models with equal weights and 23 models with regression weights produced a relative error between 5 and $10 \%$. 


\begin{tabular}{|l|c|c|c|}
\hline & \multicolumn{3}{|c|}{ Proportion in \% } \\
\hline Model & $\begin{array}{c}\text { model on the first } \\
\text { place }\end{array}$ & $\begin{array}{c}\text { model on the second } \\
\text { place }\end{array}$ & $\begin{array}{c}\text { model on the third } \\
\text { place }\end{array}$ \\
\hline Damped Trend Exponential Smoothing & 30.1 & 23.3 & 13.4 \\
\hline Linear (Holt) Exponential Smoothing & 24.7 & 21.9 & 19.4 \\
\hline Log Damped Trend Exponential Smoothing & 11.0 & 10.9 & 7.4 \\
\hline Simple Exponential Smoothing & 6.8 & 8.2 & - \\
\hline Log Simple Exponential Smoothing & 6.8 & 1.4 & 11.9 \\
\hline Log Linear (Holt ) Exponential Smoothing & 5.5 & 4.1 & - \\
\hline Log Linear Trend & 5.5 & 1.4 & 20.9 \\
\hline Random Walk with Drift & 4.1 & 12.3 & 1.5 \\
\hline Linear Trend & 4.1 & 4.1 & 10.4 \\
\hline Double Brown Exponential Smoothing & 1.4 & 4.1 & 6.0 \\
\hline Log Random Walk with Drift & - & 2.8 & 1.5 \\
\hline Mean & - & 5.5 & 9.0 \\
\hline Log Mean & - & - & \\
\hline
\end{tabular}

Source: Own processing based on data provided by Czech Statistical Office

Table 2: Individual time series models representation in combined prognoses.

3. Quality assessment of individual models and of the forecast quality of the time series

If a quality comparison is performed of the suitable individual models and the combined models, it can be stated that the results are similar. Slightly different, is the conclusion in the case of the forecast quality assessment. Table 3 offers information on the best models applied in separate food and foodstuffs groups, considering model quality on one side and forecast quality on the other. The following marking has been used in the table:

\section{$I$ - individual model}

$K 1$ - combined model with equal weights

$K 2$ - combined model regression weights.

Individual models have been placed in terms of their quality in $35.6 \%$, in terms of prognosis' quality in $24.7 \%$. Both in terms of quality and in terms of prognosis, they can be assessed in the cases of the following separate food: cereals in grain value, wheat, wheat bread, total consumption of meat, consumption of sheep meat, consumption of rabbit meat, consumption of sugar and chocolate confectionery, consumption of soda water, total fruit consumption, apples and bananas.

If the model quality is being assessed, the combined models have been placed as the better ones, in $63.4 \%$ of cases. If the size of the separate average relative forecast errors is compared, then in the case of the best individual models selected, the average relative forecast error was $6.91 \%$ (when not including extremes it was $4.22 \%$ ). In $66.6 \%$ of the cases of foodstuffs, the error was less than $5 \%$ and in the case of two other, only indicators monitored it exceeded $10 \%$ (garlic consumption, apricots consumption). In the best combined models with equal weights selected, the average relative error reached $4.44 \%$ (when not including extremes it was $3.58 \%$ ). $73 \%$ of foodstuffs consumption models showed the relative forecast error lower than $5 \%$ and in two only models of foodstuffs consumption the error was above $10 \%$ (other cereals consumption, canned milk consumption). In the best combined models with regression weights selected, the average relative forecast error was $4.3 \%$ (when not including extremes it was $3.87 \%$ ). $65.5 \%$ of foodstuffs consumption models showed the relative forecast error lower than $5 \%$ and only one model had the relative forecast error above $10 \%$ (pears consumption). 


\begin{tabular}{|l|c|c|c|c|c|c|c|c|}
\hline & \multicolumn{6}{|c|}{ Quality of Model - best models } & \multicolumn{4}{|c|}{ Quality of Prognoses - best models } \\
\hline Foodstuffs group & I & K1 & K2 & TOTAL & I & K1 & K2 & TOTAL \\
\hline Cereals and bakery products & 4 & 6 & 5 & 15 & 3 & 7 & 5 & 15 \\
\hline Meat in terms of carcass wieght & 4 & 1 & 5 & 10 & 3 & 1 & 6 & 10 \\
\hline Milk, milk products, cheese and eggs & 4 & 2 & 3 & 9 & 2 & 4 & 3 & 9 \\
\hline Fats and oils & - & 4 & 2 & 6 & 1 & 3 & 2 & 6 \\
\hline Sugar, sweets and confectionary & 3 & 1 & 3 & 7 & 2 & 3 & 2 & 7 \\
\hline Non-alcoholic beverages & 2 & 2 & 2 & 6 & 2 & 2 & 2 & 6 \\
\hline Fruits in terms of fresh & 6 & 1 & 4 & 11 & 5 & 2 & 4 & 11 \\
\hline Vegetables, pulses, potatoes & 3 & 2 & 4 & 9 & - & 4 & 5 & 9 \\
\hline TOTAL & 26 & 19 & 28 & 73 & 18 & 26 & 29 & 73 \\
\hline TOTAL in \% & 35.6 & 26.0 & 38.4 & 100 & 24.7 & 35.6 & 39.7 & 100 \\
\hline
\end{tabular}

Source: Processing based on data provided by Czech Statistical Office

Table 3: Assessment of model quality and forecast quality in separate foodstuffs groups.

\section{Conclusion}

The level of foodstuffs consumption depends on a number of factors. Not only on household incomes and foodstuffs prices, but it also depends on higher (need different word) info on foodstuffs quality, contents of preservatives, healthy lifestyle and certain "fashion waves" in liking of certain foods.

Therefore, various model procedures are being prepared for the estimation of expected foodstuffs consumption development. Usually the complex econometric models are taking into account all of the basic factors that are affected at the highest foodstuffs consumption level and structure. This way, the model has its own causal reasoning. Nevertheless, it is useful to realize that construction of such a model is not a simple task.

Here it is best to start not only from the analysis of the basic factors affecting foodstuffs demand and consumption (consumer prices, incomes, food expenditure share on total expenses etc.) but also to focus on the consumer demand research data as well. Such research aims at finding what are the items preferred by consumers, what price variations they are willing to tolerate, and what are their substitution preferences (which commodity they are willing to replace in their consumption by another food commodity) etc. Collection of all data needed and subsequent construction of such a model is an arduous and lengthy job.

Therefore, this paper concentrates on the verification of the changes of time series analysis application in short-time forecast development. Prognostic techniques using the time series model extrapolation are only based on the course of the values over time assumption and the analysis can be satisfied by the past consumption development information only. This is then more easily detected.

The results so far have shown that the prognostic procedures of this type can serve as a good alternative or as a supplement for the complex econometric models in the future foodstuffs consumption development estimation. This is especially true since the short-term prognoses have mostly shown themselves to be of comparatively good quality. Here, the classical trend models have not been applied as much anymore. However, in order to reduce the risk of forecast errors of the adaptive exponential smoothing models, or the Box-Jenkins models play the role eventually, and specifically the possibility of the individual models aggregation into combined forecasts.

Better prognostic properties of the combined models have been confirmed by the outcomes of many studies. Some better quality forecasts constructed by means of combined models have been demonstrated, e.g. in the area of mobile services consumption in the Czech Republic (Köppelová and Jindrová, 2017). In addition, Mamat et al. (2016) confirmed, using their by utilizing their analysis about the advantages of combined models use in farm machinery performance forecasts. Comparison of the individual and combined models has been offered in the studies of many other authors as well. For instance there have been promising results in the use of the combined methods or models for both Tavakkoli et al. (2015) and Deb et al. (2017). The same holds true for this paper. Based on the analyses, it is possible to state that, that in the case of most foodstuffs, these procedures 
based on the time series analysis can be applied for short-term foodstuffs consumption forecasts with success. In particular, the combination of appropriate individual models has brought about a reduction of the forecast errors and it offered comparatively high quality forecasts. This procedure can be used for the quick construction of short-term foodstuffs consumption forecasts, which serve the food producers or the business sector.

\section{Corresponding author:}

Ing. Jana Köppelová

Department of Statistics, Faculty of Economics and Management, Czech University of Life Sciences Prague, Kamýcká 129, 16500 Prague-Suchdol, Czech Republic

E-mail: koppelova@pef.czu.cz

\section{References}

[1] Arlt, J. and Arltová, M. (2009) "Ekonomické časové řady", Prague, Professional Publishing. 290 p. ISBN 978-80-86946-85-6.

[2] Cipra, T. (1986) "Analýza časových řad s aplikacemi v ekonomii", Prague, SNTL/Alfa.

[3] Barreras S. A., Sánchez L. E., Figueroa S. F., Olivas, V. J. Á. and Pérez L. C. (2014) "The use of a univariate time series model to short term forecast the behaviour of beef production in Baja California, Mexico", Veterinaria México, Vol. 45, pp. 1-9. ISSN 03015092.

[4] Deb, Ch., Zhang, F., Yang, J., Lee, S. E. and Shah, K. W. (2017) "A review on time series forecasting techniques for building energy consumption“, Renewable and Sustainable Energy Reviews, Vol. 74, pp. 902-924. ISSN 13640321.

[5] De Vogli, R., Kouvonen, A. and Gimeno, D. (2014) "The influence of market deregulation on fast food consumption and body mass index: a cross-national time series analysis", Bulletin of the World Health Organization, Vol. 92, No. 2, pp. 99-107A. DOI 10.2471/BLT.13.120287.

[6] Hindls, R., Hronová, S. and Novák, I. (2000) "Metody statistické analýzy pro ekonomy", Prague. ISBN 80-7261-013-9.

[7] Chen, D., Gao, W., Chen, Y. and Zhang, Q. (2010) "Ecological footprint analysis of food consumption of rural residents in China in the latest 30 years", Agriculture and Agricultural Science Procedia, Vol. 1, pp. 106-115. ISSN 22107843.

[8] Christodoulos, Ch., Michalakelis, CH. and Varoutas, D. (2011) "On the combination of exponential smoothing and diffusion forecasts: An application to broadband diffusion in the OECD area“, Technological Forecasting and Social Change, Vol. 78, No. 1, pp. 163-170. ISSN 0040-1625. DOI 10.1016/j.techfore.2010.08.007.

[9] Kába, B. (1997) "Konstrukce kombinovaných předpovědí časových řad ekonomických ukazatelů", in: Zborník vedeckých prác z MVD, Nitra.

[10] Köppelová, J. and Jindrová, A. (2017) "Comparative Study of Short-Term Time Series Models: Use of Mobile Telecommunication Services in CR Regions“, Agris on-line Papers in Economics and Informatics, Vol. 9, No. 1, pp. 77-89. ISSN 18041930. DOI 10.7160/aol.2017.090107.

[11] Mamat, T., Weimin, D. and Jianhua, X. (2016) "Research of combination prediction model for time series: a case study in total power of agriculture machinery“", Journal of Nanjing Agricultural University, Vol. 39, No. 4, pp. 688-695. ISSN 10002030.

[12] Martin, V., Hurn, S. and Harris, D. (2013) "Econometric modelling with time series", Cambridge Books. ISBN 978-0-521-19660-4.

[13] Náglová, Z. and Horáková, T. (2016) "Influence of Qualitative Factors on Quantitative Determinants in the Czech Meat Industry Economy“, AGRIS On-line Papers in Economics and Informatics, Vol. 8, No. 4, pp. 111-123. ISSN 1804-1930. DOI 10.7160/aol.2016.080410. 
[14] Notarnicola, B., Tassielli, G., Renzulli, P. A., Castellani, V. and Sala, S. (2016) "Environmental impacts of food consumption in Europe“, Journal of Cleaner Production, Vol. 140, pp. 753-765. ISSN 0959-6526. DOI 10.1016/j.jclepro.2016.06.080.

[15] Olsen, S. O. and Tuu, H. H. (2017) "Time perspectives and convenience food consumption among teenagers in Vietnam: The dual role of hedonic and healthy eating values", Food Research International. ISSN 0963-9969. DOI 10.1016/j.foodres.2017.05.008.

[16] Papagera, A., Ioannou, K., Zaimes, G., Iakovoglou, V. and Simeonidou, M. (2014) "Simulation and Prediction of Water Allocation Using Artificial Neural Networks and a Spatially Distributed Hydrological Model", Agris on-line Papers in Economics and Informatics, Vol. 6, No. 4, pp. 101-111. ISSN 1804-1930.

[17] Pletichová, D. and Gebeltová, Z. (2013) "Development of Market Prices of Agricultural Land within the Conditions of the EU“, Agris on-line Papers in Economics and Informatics, Vol. 5, No. 3, pp. 65-78. ISSN 1804-1930.

[18] Reboiro-Jato, M., Glez-Dopazo, J., Glez, D., Laza, R., Gálvez, J. F., Pavón, R. Glez-Peňa, D. and Fdez-Riverola, F. (2011) "Using inductive learning to assess compound feed production in cooperative poultry farms“, Expert Systems With Applications, Vol. 38, No. 11, pp. 14169-14177. ISSN 09574174.

[19] Sachs, L. (1984) "Applied Statistics". Springer-Verlag, New York.

[20] SAS/ETS User`s Guide, Version 6. (1993) SAS Institute Inc., Cary, USA.

[21] Seger, J. and Hindls, R. (1993) "Statistické metody v ekonomii", Prague: H\&H. ISBN 80-85787-26-1.

[22] Smutka, L., Steininger, M. and Miffek, O. (2009) "World agricultural production and consumption“", Agris on-line Papers in Economics and Informatics, Vol. 1, No. 2, pp. 3-12. ISSN 1804-1930.

[23] Tavakkoli, A., Hemmasi, A. H., Talaeipour, M., Bazyar, B. and Tajdini, B. (2015) "Forecasting of Particleboard Consumption in Iran Using Univariate Time Series Models“, Bio Resources, Vol. 10, No. 2, pp. 2032-2043. ISSN 19302126.

[24] Xu, G. and Wang, W. (2010) "Forecasting China's natural gas consumption based on a combination model“, Journal of Natural Gas Chemistry, Vol. 19, No. 5, pp. 493-496. ISSN 10039953. 